\title{
Sustentabilidade econômica: a estratégia de diversificação de portfólio de um fabricante de aeronaves
}

\author{
Rafael Bichone* \\ Monica Franchi Carniello**
}

\begin{abstract}
Resumo: A atual dinâmica da economia e a maior disponibilidade de informações têm levado as empresas a buscarem um maior equilíbrio entre as três bases da sustentabilidade empresarial: econômica, ambiental e social. Ao mesmo tempo, essas empresas têm que se estabelecer em uma arena competitiva cada vez mais dinâmica, onde o posicionamento pode ser facilmente copiado pelos competidores e o aumento de produtividade não vem acompanhado de uma rentabilidade duradoura. Desta forma, as empresas precisam criar e manter uma proposta de valor singular, estabelecendo atividades únicas para diferenciá-las de seus competidores. Neste contexto, o objetivo deste estudo é analisar como um fabricante de aeronaves usou suas principais competências em alinhamento com seus objetivos estratégicos, nos últimos cinco anos, de forma a estabelecer um portfólio de produtos único, diversificando suas fontes de receita e estabelecendo um diferencial competitivo difícil de ser copiado. Com base nos relatórios financeiros dessa empresa, vemos que os resultados da estratégia de ampliação de portfólio permitiram à empresa diversificar suas fontes de receita e diminuir seu risco, num cenário econômico marcado pela crise financeira iniciada em 2008.
\end{abstract}

Palavras-chave: Sustentabilidade econômica, Administração, Estratégia, Portfólio.

Classificação Jel: M16.

* Professor titular de econometria em São José dos Campos S.P. E-mail: rbichone@gmail.com

** Professora assistente doutora da Universidade de Taubaté. E-mail: monicafcarniello@gmail.com 


\begin{abstract}
The current dynamics of the economy and a greater quantity of available information has taken companies to search for a balance in the three aspects of corporate sustainability: the economic, environmental and social aspects. At the same time, those companies have to establish themselves in a competitive arena increasingly dynamic, where the positioning can be easily copied by competitors and the rise in productivity is not accompanied by a durable profitability. Therefore, companies need to create and keep a differentiated value proposition, establishing unique activities to differentiate themselves of their competitors. The objective of this study is to analyze how an aircraft manufacturer used its main competences to align its strategic objectives, in the last five years, with a unique product portfolio, diversifying its sources of revenue and establishing a competitive differential tough to be copied. Based on the company's financial reports, we see that the results of the adopted portfolio diversification strategy allowed the company to diversify its revenue sources and reduce its risk, in an economic scenario marked by the financial crisis started in 2008 .
\end{abstract}

Keywords: Economic sustainability, Strategic management, Portfolio diversification.

Jel Classification: M16.

\title{
1 Introdução
}

A atual dinâmica da economia e a maior disponibilidade de informações têm levado as empresas a buscarem um maior equilíbrio entre as três bases da sustentabilidade empresarial: econômica, ambiental e social. Entretanto, esses fundamentos da sustentabilidade podem ser vistos como conflitantes, uma vez que a busca por resultados financeiros imediatos exerce pressão sobre as empresas em seu cotidiano. (Jappur et al., 2008).

Ao mesmo tempo, as empresas estão inseridas em um cenário competitivo dinâmico, onde as estratégias de posicionamento devem ser revistas constantemente, uma vez que estas podem ser facilmente copiadas pelos seus concorrentes. (Jappur et al., 2008). Este mesmo autor defende que este tipo de atitude pode levar a destruição mútua das empresas, gerando impactos negativos sobre todos os aspectos de sustentabilidade. Além disso, segundo Porter, 1996, a constante busca por aumentos de produtividade nem sempre vem acompanhada por uma rentabilidade duradoura, levando as empresas à necessidade de criar uma proposta de valor tão singular que seja extremamente improvável que seus competidores possam copiá-la. Porter, 1996, defende, assim, que a essência da estratégia está na diferenciação das atividades.

As empresas precisam, dessa forma, alinhar suas estratégias competitivas com suas competências organizacionais e, além disso, estimular o aprendizado organizacional, de forma a propagar as melhores práticas e conhecimentos por toda a empresa, principalmente aquelas que são únicas dentro da corporação. (Fleury, M. T. L.; Fleury, A. C. C., 2003, 2004)

Neste contexto, o presente artigo tem por objetivo estudar a estratégia de diversificação de portfólio de um fabricante de aeronaves, através do 
levantamento de alinhamento das estratégias corporativas com suas competências organizacionais, e o resultado dessas ações tanto na diversificação de fontes de receita da empresa como na redução do seu risco, num cenário marcado pela crise financeira iniciada em 2008. A importância deste estudo se destaca por demonstrar como uma empresa inserida em um mercado global conseguiu obter, de seus próprios recursos, a capacitação necessária para ampliar sua gama de produtos e, assim, minimizar os possíveis efeitos negativos que a crise econômica mundial poderia gerar sobre seus resultados, comprometendo dessa forma a sua perenidade.

$\mathrm{O}$ artigo é divido nos seguintes capítulos. O primeiro traz as teorias de Administração Estratégica, confrontando as abordagens clássicas com novas proposições. O segundo capítulo aborda os aspectos de Sustentabilidade Empresarial, com ênfase aos possíveis conflitos entre as dimensões de sustentabilidade e a mudança da lógica da estratégia empresarial. O terceiro capítulo revisa os relatórios financeiros da empresa, destacando a ampliação do portfólio de produtos e os resultados mensuráveis de tal alteração. Finalmente, o último capítulo discute os resultados demonstrados pela empresa e traça uma relação entre a estratégia e os resultados obtidos.

\section{Referencial teórico}

\subsection{Administração Estratégica}

Os conceitos de administração estratégica começaram a ganhar relevância quando as empresas perceberam a necessidade de adotar medidas que as diferenciassem de seus competidores. Em 1980, Michael Porter, em seu livro "Competitive Strategy", definiu a estratégia competitiva como o resultado de ações para criar um posicionamento sustentável em sua indústria de atuação. Nesta obra, ele sustenta três tipos de estratégias genéricas, que podem ser usadas isoladamente ou em combinações para criar uma posição de diferenciação em longo prazo, gerando uma vantagem competitiva sustentável: a estratégia de custo, onde a empresa busca a máxima eficiência produtiva, a estratégia de diferenciação, onde as empresas buscam diferenciar-se pela marca, reputação ou tecnologia e a estratégia de foco, onde se escolhe um determinado nicho de mercado a ser atendido em suas necessidades específicas.

Entretanto, este tipo de posicionamento começou a ser criticado e complementado, como mostra a obra de Manoel et al., 1997, intitulada "Porter Revisitado: Análise Crítica da Tipologia Estratégica do Mestre.” Neste texto, é apresentado o conceito de Resource-Based View, teoria estratégica baseada na análise interna dos recursos e competências que cada empresa possui.

Um pouco antes, em 1996, o próprio Michael Porter revisitara sua obra para atualizar os conceitos de administração estratégica. Nessa nova leitura, o autor defende que o posicionamento de diferenciação, antes defendido, é estático demais para mercados dinâmicos. Ao escolher seu posicionamento e torná-lo evidente, uma empresa torna fácil a seus competidores a cópia deste 
posicionamento e, dessa forma, a vantagem competitiva anteriormente adquirida rapidamente deixa de existir. Além disso, o fato das empresas se copiarem leva a um nível de concorrência mutuamente destrutível, gerando frustração entre ganhos de produtividade e perda de lucratividade. Por isso, o autor defende que as empresas devem buscar a melhoria em todos os seus pontos de atividades, criando dessa forma posições competitivas viáveis mais improváveis de serem copiadas. Nas próprias palavras do autor, "estratégia competitiva tem a ver com ser diferente. Significa escolher deliberadamente um conjunto diferente de atividades para distribuir um mix único de valor". Para sustentar essa visão, Sharkie, 2003, defende que a sustentabilidade da vantagem competitiva é obtida através do desenvolvimento de atividades coordenadas e complementares, direcionadas a criar uma estratégia de diferenciação e uma oferta única aos clientes.

Estes novos posicionamentos levaram ao conceito de transição de eficiência individual para eficiência coletiva. Segundo esta nova abordagem, a competitividade estará cada vez mais vinculada ao desempenho de redes interorganizacionais e não mais de empresas isoladas. (Fleury, M. T. L.; Fleury, A. C. C., 2003). Contudo, a criação destas redes de empresas apresenta uma dimensão regional que, por sua vez, está vinculada ao movimento de globalização das grandes empresas. Este texto propõe abordagens alternativas ao modelo de Porter, onde a definição de estratégia competitiva parte do entendimento das possibilidades estratégicas que possam ser criadas e operacionalizadas "de dentro para fora" em cada organização. As empresas devem encarar a aprendizagem como um meio para alinhar as competências organizacionais com a estratégia empresarial, como demonstrado na figura 1: o ciclo de estratégia (Fleury, M. T. L.; Fleury, A. C. C., 2003).

Para tanto, se faz necessário entender a competência individual como "um conjunto de conhecimentos, habilidades e atitudes que justificam um alto desempenho, na medida em que há também um pressuposto de que os melhores desempenhos estão fundamentados na inteligência e na personalidade das pessoas." (Fleury, M. T. L.; Fleury, A. C. C., 2004). Já o conceito de competência organizacional encara as organizações como um conjunto de recursos - resource based view of the firm. Esta forma de entender a competência nas organizações compreende que a empresa tem um portfólio de infraestrutura, financeiro, de marca e reputação, de sistemas administrativos, de cultura organizacional e de recursos humanos, reforçando a importância de se centrar a elaboração da estratégia em grupos específicos de recursos, que irão garantir a lucratividade a longo prazo, diferenciando recursos de competências. "Um recurso é algo que a organização possui ou tem acesso, mesmo que esse acesso seja temporário [...] uma competência é uma habilidade para fazer alguma coisa [...] uma competência é construída a partir de um conjunto de 'blocos' denominados recursos" (Mills et al., 2002). 
Figura 1: o ciclo de estratégia (Fleury, M. T. L.; Fleury, A. C. C., 2003)

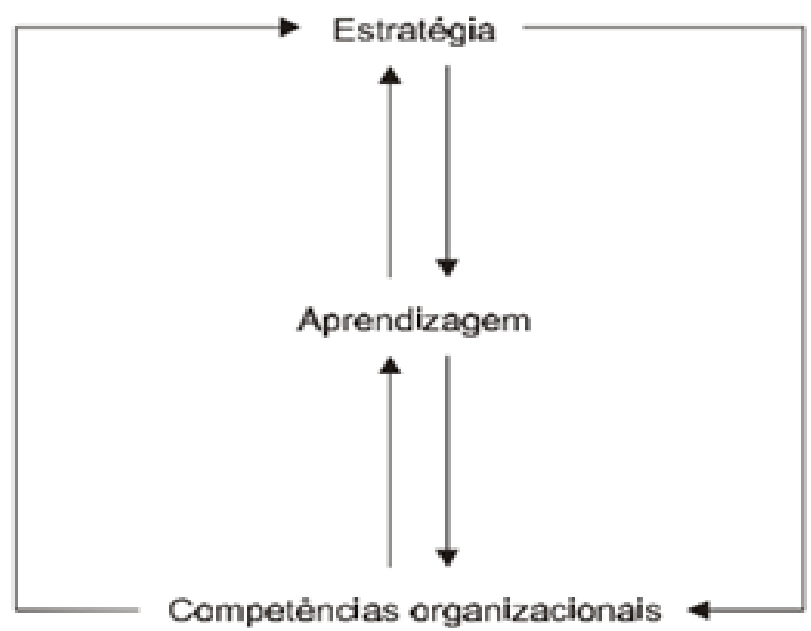

Fonte: Fleury, M. T. L.; Fleury, A. C. C. (2003)

Em 1990, Prahalad e Hamel defenderam que a competitividade de uma empresa é definida pela relação dinâmica entre competências organizacionais e a estratégia competitiva. Com isso, cria-se um ciclo contínuo entre a formulação de estratégia e a formulação de competências (figura 2: Círculo dinâmico de estratégia e competências.(Prahalad; Hamel, 1990).

Estes autores concluem, então, que as competências essenciais devem respeitar três critérios:

a. Oferecer benefícios reais aos consumidores

b. Ser difíceis de serem copiadas pelos competidores

c. Permitir o acesso a diferentes mercados

A partir deste prisma, as empresas devem identificar as competências essenciais de seu negócio e aquelas necessárias a cada atividade, que formarão as competências organizacionais. Mills et al., (2002), buscando sintetizar essa nova abordagem, definem um quadro-resumo das competências organizacionais tabela 1: quadro-resumo das competências organizacionais. (MILLS et al., 2002). 
Figura 2: Círculo dinâmico de estratégia e competências.(PRAHALAD;

HAMEL, 1990)

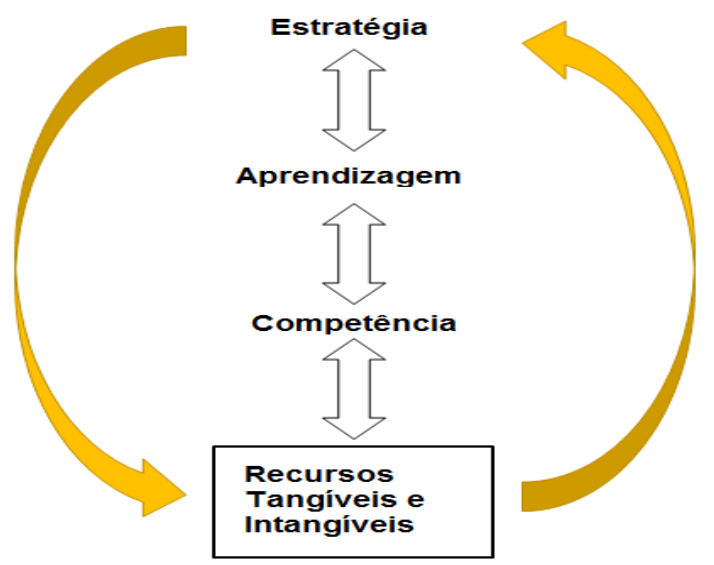

Fonte: Prahalad, C. K.; Hamel, G. (1990)

A proposta de Fleury e Fleury (2004) traz o conceito de empresas que competem por produtos inovadores. Segundo os autores, as empresas que se inserem neste cenário precisam investir de forma constante em conceitos novos em termos de produtos e serviços para clientes e segmentos para mercados específicos. O sucesso dessas empresas é obtido pela criação sistemática de produtos inovadores, tornando obsoletos tanto seus próprios produtos como os da concorrência. A Embraer, empresa que atua no segmento aeronáutico, é um exemplo que ilustra este tipo de posicionamento. Seu desafio é desenvolver conceitos de aeronaves para serem comercializadas em mercado onde os clientes são mais exigentes quanto a inovação do que em outros mercados.

Desta forma, a vantagem competitiva criada pela organização é que vai determinar a diferença de seus resultados com outras empresas. Segundo Brito e Brito (2012), uma proposta para se medir a vantagem competitiva e seus efeitos sobre o desempenho financeiro, é o conjunto formado entre lucratividade e aumento de participação de mercado. 
Tabela 1: quadro-resumo das competências organizacionais. (Mills et al., 2002)

\begin{tabular}{|c|c|}
\hline Competências essenciais & $\begin{array}{c}\text { Competências e atividades mais elevadas, no nível corporativo, } \\
\text { que são chave para a sobrevivência da empresa e centrais para } \\
\text { sua estratégia. }\end{array}$ \\
\hline Competências distintivas & $\begin{array}{c}\text { Competências e atividades que os clientes reconhecem como } \\
\text { diferenciadoras de seus concorrentes e que provêm vantagens } \\
\text { competitivas. }\end{array}$ \\
\hline $\begin{array}{l}\text { Competências } \\
\text { organizacionais ou das } \\
\text { unidades de negócios }\end{array}$ & $\begin{array}{l}\text { Competências e atividades-chaves, esperadas de cada unidade } \\
\text { de negócios da empresa. }\end{array}$ \\
\hline Competências de suporte & Atividade que é valiosa para apoiar um leque de competências \\
\hline Capacidades dinâmicas & $\begin{array}{c}\text { Capacidade de uma empresa de adaptar suas competências pelo } \\
\text { tempo. É diretamente relacionada aos recursos importantes para } \\
\text { a mudança. }\end{array}$ \\
\hline
\end{tabular}

Fonte: Mills, J.; Platts, K.; Bourne, M.; Richards, H. (2002)

\subsection{Sustentabilidade Econômica}

No final do século XX, em uma Assembleia Geral da ONU, é formada a definição de desenvolvimento sustentável: "Desenvolvimento sustentável é aquele que atende as necessidades do presente sem comprometer a possibilidade das gerações futuras" (CMMAD, 1991). Sequencialmente, as empresas aderem ao desenvolvimento sustentável, num movimento que, diferente do movimento da gestão da qualidade, vem, num primeiro momento, de fora para dentro. (Barbieri et al., 2010). As empresas aderem a este sistema mais como uma forma de oposição às críticas recebidas pelas empresas de inúmeras entidades governamentais, que as apontam como responsáveis pelos processos não só de degradação ambiental como pelo processo de degradação social em todo o planeta.

Essa é, então, uma das primeiras respostas da sociedade ao modelo anterior de produção em massa e consumismo gerado pelo crescimento econômico do final do século XX. Autores como Canclini, 1991, definem que "Consumir é participar de um cenário de disputas por aquilo que a sociedade produz e pelos modos de usá-los". Esse autor esclarece que a apropriação de objetos como forma de distinção entre as pessoas numa sociedade não satisfaz às suas reais necessidades e sim a impossibilidade dos outros de possuírem aquilo que somente alguns possuem. Como exemplo, o autor destaca uma peça indígena ou um veículo importado, destacando que ambos possuem elementos para quem não os possui saber seus significados socioculturais.

No início do século XXI são mensurados os primeiros resultados das empresas que anteriormente haviam aderido aos padrões de sustentabilidade concebidos pela sociedade e onde, pela primeira vez, nota-se que os resultados dessas empresas reduzem o risco como um todo, "determinando a redução do 
custo do capital e o aumento do valor econômico." (Simone; Quelhas, 2006). Dada a relação de menor risco e de aumento do valor econômico, investidores começam a preferir empresas listadas no índice de sustentabilidade da Bovespa. (Bovespa, 2013).

Dentro das empresas, reforça-se o entendimento de que os recursos naturais não eram inesgotáveis como resultado da percepção da humanidade sobre a natureza. (Jappur et al., 2008). Ao mesmo tempo, surge o conceito do tripple-bottom-line da sustentabilidade corporativa. Neste conceito, deve-se então buscar o equilíbrio nas dimensões econômica, ambiental e social de uma empresa, que são muitas vezes conflitantes entre si, pelo fato das corporações usualmente buscarem apenas os resultados financeiros de curto prazo. $\mathrm{O}$ conceito, então, tem o objetivo de integrar as estratégias empresariais com a sustentabilidade, se propagando por toda a cadeia produtiva.

\subsection{A Diversificação de Portfólio de um Fabricante de Aeronaves e seus Resultados Econômico-Financeiros}

Através do levantamento dos relatórios financeiros de um fabricante de aeronaves, obtidos através do site da CVM - Comissão de Valores Mobiliários (CVM, acesso em junho de 2013), pôde-se levantar o perfil de entrega, em termos de quantidades entregues por modelo de aeronave, entre os anos de 2008 e 2012 , que estão resumidos na tabela 2 - entregas de aeronaves por segmento.

A empresa divide seus produtos em três tipos de segmentos: aviação comercial, aviação executiva e aviação de defesa e governo. No segmento de aviação comercial, dentro do período analisado, verifica-se que não houve a inserção de nenhum modelo de aeronave e, por outro lado, verifica-se a queda no número de aeronaves entregues do modelo ERJ 145 e do modelo Embraer 170.

Já no segmento de aviação executiva, verifica-se a inclusão do modelo Phenom 100 no ano de 2008 (Embraer S.A., 2008), dos modelos Phenom 300 e Lineage 1000 no ano de 2009 (Embraer S.A., 2009) e do modelo Legacy 650 no ano de 2010 (Embraer S.A., 2010).

No segmento de defesa e governo, verifica-se a inclusão do modelo Super Tucano no ano de 2010 (Embraer S.A., 2010) e do modelo Emb 145 Aew\&C no ano de 2012 (Embraer S.A., 2012). Também vale destacar que os modelos Embraer 175 e Embraer 190, criados para o segmento de aviação comercial, são entregues esporadicamente nos segmentos de aviação executiva e de defesa e governo, assim como os modelos Phenom 100 e Legacy 600, criados para o segmento de aviação executiva, são entregues esporadicamente no segmento de defesa e governo, o que reforça a visão de que esta empresa utiliza seu portfólio de produtos para atender todos os possíveis segmentos de clientes. 
Sustentabilidade Econômica: A Estratégia de Diversificação de Portfólio de um Fabricante ..

Tabela 2: Entregas de aeronaves por segmento

(Embraer S.A., 2008, 2009, 2010, 2011, 2012)

\begin{tabular}{|c|c|c|c|c|c|c|}
\hline Segmento & Modelo de aeronave & 2008 & 2009 & 2010 & 2011 & 2012 \\
\hline \multirow{7}{*}{ Aviação comercial } & & 162 & 122 & 100 & 105 & 106 \\
\hline & ERJ 145 & 6 & 7 & 6 & 2 & \\
\hline & EMBRAER 170 & 9 & 22 & 11 & 1 & 1 \\
\hline & EMBRAER 175 & 55 & 11 & 8 & 10 & 20 \\
\hline & EMBRAER 190 & 78 & 62 & 58 & 68 & 62 \\
\hline & EMBRAER 195 & 14 & 20 & 17 & 24 & 23 \\
\hline & & 36 & 115 & 144 & 99 & 99 \\
\hline \multirow{5}{*}{ Aviação executiva } & Phenom 100 & 2 & 93 & 100 & 41 & 29 \\
\hline & Phenom 300 & & 1 & 26 & 42 & 48 \\
\hline & Legacy 600 & 33 & 18 & 3 & & \\
\hline & Legacy 650 & & & 7 & 13 & 19 \\
\hline & Lineage 1000 & & 3 & 5 & 3 & 3 \\
\hline \multirow{9}{*}{ Defesa e Governo } & EMBRAER 175 & 1 & & 3 & & \\
\hline & & 6 & 7 & 37 & 8 & 16 \\
\hline & Super Tucano & & & 35 & 8 & 14 \\
\hline & ERJ 135 & 2 & 1 & 1 & & \\
\hline & ERJ 145 & 1 & & & & \\
\hline & EMB 145 AEW\&C & & & & & 2 \\
\hline & Phenom 100 & & 4 & & & \\
\hline & Legacy 600 & 3 & & 1 & & \\
\hline & EMBRAER 190 & 0 & 2 & & & \\
\hline Total de aeronaves & & 204 & 244 & 281 & 212 & 221 \\
\hline
\end{tabular}

Fonte: Embraer S.A.

Tabela 3: Resultados econômicos / financeiros

(Embraer S.A., 2008, 2009, 2010, 2011, 2012)

\begin{tabular}{l|r|r|r|r|r}
\hline \multicolumn{1}{c|}{ Item } & \multicolumn{1}{c|}{$\mathbf{2 0 0 8}$} & $\mathbf{2 0 0 9}$ & $\mathbf{2 0 1 0}$ & $\mathbf{2 0 1 1}$ & \multicolumn{1}{c}{$\mathbf{2 0 1 2}$} \\
\hline $\begin{array}{l}\text { Carteira de } \\
\text { pedidos }\end{array}$ & USD 20,90 & USD 16,60 & USD & USD 15,40 & USD \\
$\begin{array}{l}\text { Receita líquida } \\
\begin{array}{l}\text { Custo dos } \\
\text { produtos }\end{array}\end{array}$ & $\mathrm{R} \$ 11,75$ & $\mathrm{R} \$ 10,81$ & $\mathrm{R} \$ 9,38$ & $\mathrm{R} \$ 9,86$ & $\mathrm{R} \$ 12,50$ \\
vendidos & $\mathrm{R} \$ 9,34$ & $\mathrm{R} \$ 8,73$ & $\mathrm{R} \$ 7,58$ & $\mathrm{R} \$ 7,64$ & $\mathrm{R} \$ 9,25$ \\
$\begin{array}{l}\text { Lucro bruto } \\
\text { Margem bruta }\end{array}$ & $\mathrm{R} \$ 2,40$ & $\mathrm{R} \$ 2,08$ & $\mathrm{R} \$ 1,80$ & $\mathrm{R} \$ 2,22$ & $\mathrm{R} \$ 2,95$ \\
$\begin{array}{l}\text { Despesas } \\
\text { operacionais }\end{array}$ & $\mathrm{R} \$ 1,5 \%$ & $19,20 \%$ & $19,20 \%$ & $22,50 \%$ & $24,20 \%$ \\
\hline
\end{tabular}


Continuação Tabela 3

\begin{tabular}{l|c|c|c|c|c}
\hline \multicolumn{1}{c|}{ Item } & $\mathbf{2 0 0 8}$ & $\mathbf{2 0 0 9}$ & $\mathbf{2 0 1 0}$ & $\mathbf{2 0 1 1}$ & $\mathbf{2 0 1 2}$ \\
\hline $\begin{array}{l}\text { Lucro } \\
\text { operacional }\end{array}$ & $\mathrm{R} \$ 1,11$ & $\mathrm{R} \$ 0,73$ & $\mathrm{R} \$ 0,69$ & $\mathrm{R} \$ 0,52$ & $\mathrm{R} \$ 1,22$ \\
$\begin{array}{l}\text { Margem } \\
\text { operacional }\end{array}$ & $9,50 \%$ & $6,80 \%$ & $7,30 \%$ & $5,30 \%$ & $10,00 \%$ \\
$\begin{array}{l}\text { EBITDA } \\
\text { ajustado }\end{array}$ & $\mathrm{R} \$ 1,50$ & $\mathrm{R} \$ 1,16$ & $\mathrm{R} \$ 1,07$ & $\mathrm{R} \$ 0,92$ & $\mathrm{R} \$ 1,77$ \\
$\begin{array}{l}\text { Margem } \\
\text { EBITDA }\end{array}$ & $12,80 \%$ & $10,70 \%$ & $11,40 \%$ & $9,40 \%$ & $14,50 \%$ \\
$\begin{array}{l}\text { ajustada } \\
\text { Lucro líquido }\end{array}$ & $\mathrm{R} \$ 0,43$ & $\mathrm{R} \$ 0,89$ & $\mathrm{R} \$ 0,57$ & $\mathrm{R} \$ 0,16$ & $\mathrm{R} \$ 0,70$ \\
$\begin{array}{l}\text { Margem líquida } \\
\text { Lucro por ação }\end{array}$ & $3,7 \%$ & $8,30 \%$ & $6,10 \%$ & $1,60 \%$ & $5,70 \%$ \\
$\begin{array}{l}\text { Quantidade de } \\
\text { ações }\end{array}$ & $\mathrm{R} \$ 0,59$ & $\mathrm{R} \$ 1,24$ & $\mathrm{R} \$ 0,79$ & $\mathrm{R} \$ 0,22$ & $\mathrm{R} \$ 0,96$ \\
\hline
\end{tabular}

Obs: valores monetários em bilhões.

Fonte: Embraer S.A.

\section{Método}

De forma resumida, a tabela 4 mostra os principais delineamentos da metodologia utilizada neste trabalho, bem como as principais referências para substanciá-la:

Tabela 4 - Classificação da metodologia utilizada

\begin{tabular}{|c|c|c|}
\hline Classificação & Justificativa & Referências \\
\hline Quantitativa & $\begin{array}{l}\text { Medir os resultados } \\
\text { financeiros obtidos com a } \\
\text { diversificação de portfólio. }\end{array}$ & (Sampieri et al., 2006) \\
\hline Exploratória & $\begin{array}{l}\text { Estudar os Relatórios de } \\
\text { Relações com Investidores, } \\
\text { buscando as estratégias e os } \\
\text { resultados obtidos. }\end{array}$ & (Richardson, 1999) \\
\hline Bibliográfica e documental & $\begin{array}{l}\text { As fontes principais são } \\
\text { relatórios e livros que } \\
\text { sustentam a argumentação } \\
\text { da pesquisa. }\end{array}$ & $\begin{array}{c}\text { (Duarte; Barros, 2005; Lima, } \\
\text { 2008) }\end{array}$ \\
\hline Fontes de papel & & (Richardson, 1999) \\
\hline
\end{tabular}

Fonte: Richardson, R. J. (1999)

Esta pesquisa explorou os documentos publicados na web site da Comissão de Valores Mobiliários (CVM, 2013), na seção Participantes do Mercado; Companhias Abertas; ITR, DFP, IAN, IPE e outras Informações; Consulta por ordem alfabética. Desta seção, foram levantados os Relatórios de Relações com Investidores dos últimos cinco exercícios fiscais finalizados até a data da presente pesquisa.

Finalmente, a análise dos relatórios foi focada nas estratégias adotadas pela empresa para diversificar seu portfólio e quais foram os resultados obtidos 
pela empresa após a adoção de tais medidas.

\section{Resultados e discussão}

Conforme levantado no capítulo 2.3, o fabricante de aeronaves analisado ampliou seu portfólio de produtos de forma a atender todos os segmentos de mercado que a empresa se propõe a atuar: aviação comercial, aviação executiva e aviação de defesa e governo.

Com base nos relatórios financeiros dessa empresa e da análise de variação de alguns importantes pontos dos resultados obtidos, pôde-se verificar que, entre os anos de 2008 e 2012, houve significante incremento do Lucro líquido, do Lucro por ação e da Margem líquida, conforme demonstra a tabela 5. Os incrementos obtidos por essas contas, acima de 50\%, demonstram a relevância da estratégia adotada pela empresa quando, no mesmo período, verificou-se uma redução de $40 \%$ na carteira de pedidos. É ainda de extrema importância salientar que o período de tempo analisado foi marcado por uma crise econômica iniciada em 2008 e cujos efeitos perduraram até a publicação do presente artigo.

Tabela 5 - Variação dos resultados entre 2008 e 2012

\begin{tabular}{l|c}
\hline \multicolumn{1}{c|}{ Item } & Variação entre 2008 e 2012 \\
\hline Lucro líquido & $63 \%$ \\
Lucro por ação & $63 \%$ \\
Margem líquida & $54 \%$ \\
Despesas operacionais & $34 \%$ \\
Lucro bruto & $23 \%$ \\
Margem bruta & $18 \%$ \\
EBITDA ajustado & $18 \%$ \\
Margem EBITDA ajustada & $13 \%$ \\
Lucro operacional & $9 \%$ \\
Margem operacional & $5 \%$ \\
Receita líquida & $4 \%$ \\
Quantidade de ações & $0 \%$ \\
Custo dos produtos vendidos & $-1 \%$ \\
Carteira de pedidos & $-40 \%$ \\
\hline
\end{tabular}

Fonte: Elaborado pelo autor

Como resultado da diversificação de portfólio demonstrada na tabela 2, verificamos as alterações de participação dos diferentes segmentos de atuação da empresa, conforme expressado na figura 3. O segmento de aviação comercial representa a principal fonte de receitas da empresa, porém, devido à diversificação de fontes de receita, sua participação é reduzida de $67 \%$ para $61 \%$. Os destaques são os segmentos de aviação executiva e de aviação de defesa e governo, cujas participações no faturamento da empresa tiveram aumentos de $14 \%$ para $21 \%$ e de $8 \%$ para $17 \%$, respectivamente. Cabe destacar que a partir do ano de 2009 a empresa não mais destacou o faturamento do segmento de 
serviços.

\section{Figura 3 - Variação de participação das receitas}

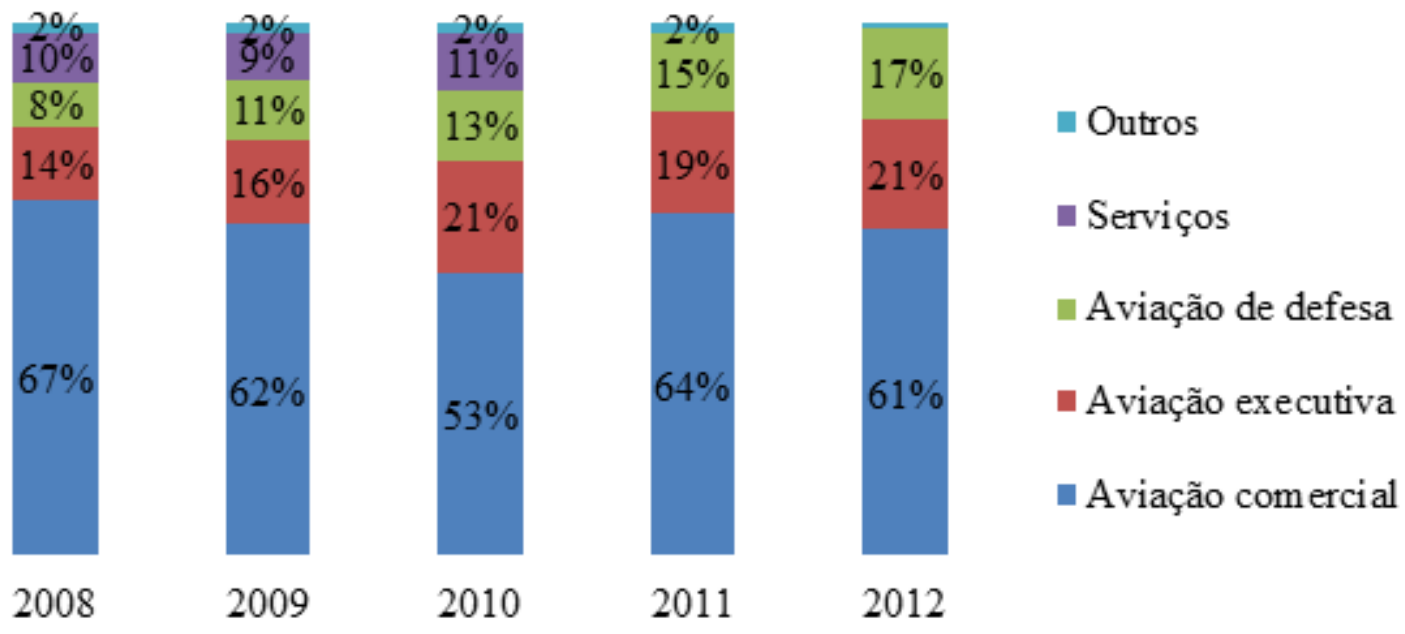

Fonte:Elaborado pelo autor

\section{Considerações finais}

Através de uma estratégia de diversificação de portfólio, que tomou proveito de suas competências internas, verificamos que a empresa fabricante de aeronaves estudada obteve relevantes resultados econômico-financeiros no período compreendido entre os anos de 2008 e 2012, além de alterar a participação na receita de cada um de seus segmentos de atuação: aviação comercial, aviação executiva e aviação de defesa e governo.

De um lado, os resultados financeiros resultaram num lucro por ação que cresceu $63 \%$ no período analisado, em um tempo marcado por grandes incertezas no mercado de ações, provocadas pela crise financeira iniciada em 2008 e cujos efeitos perduravam até a publicação deste artigo.

Por outro lado, junto com o aumento de $63 \%$ no lucro líquido, a empresa alterou a participação de cada um dos segmentos de atuação em sua receita, com diminuição percentual do mercado de aviação comercial e aumentos percentuais nos segmentos de aviação executiva e de aviação de defesa e governo, o que nos leva a concluir que a empresa diminuiu sua dependência, em termos de receita, do mercado de aviação comercial e obteve elevação de faturamento dos outros segmentos, levando a uma diminuição de seu risco empresarial. 


\section{Referências}

Barbieri, J. C.; Vasconcelos, I. F. G. De; Andreassi, T.; Vasconcelos, F. C. DE. (2010). Inovação e Sustentabilidade: Novos Modelos e Proposições. RAE, v. 50, n. 2, p. $146-154$.

Bovespa (2013). Disponível em: <www.bmfbovespa.com.br>. .

Brito, R. P. De; Brito, L. A. L. (2012 ). Vantagem competitiva, criação de valor e seus efeitos sobre o desempenho. RAE, v. 52, n. 1, p. 70-84.

Canclini, N. (1991).O Consumo Serve para Pensar.pdf. Diálogos de la Comunicación, p. 8. Lima.

CMMAD. (1991). Comissão Mundial sobre Meio Ambiente e Desenvolvimento. Rio de Janeiro.

CVM. Comissão de Valores Mobiliários. (2013). Disponível em: <http://www.cvm.gov. br/>. Acesso em: 6/2/2013.

Duarte, J.; Barros, A. (2005). Métodos e Técnicas de Pesquisa em Comunicação. São Paulo: Atlas.

Embraer S.A. (2008). Nossos Resultados, Demonstrações Financeiras 2008. São Paulo.

Embraer S.A. (2009). Nossos Resultados, Demonstrações Financeiras 2009. São Paulo.

Embraer S.A. (2010). Nossos Resultados, Demonstrações Financeiras 2010. São Paulo.

Embraer S.A. (2011). Nossos Resultados, Demonstrações Financeiras 2011. São Paulo.

Embraer S.A. (2012). Nossos Resultados, Demonstrações Financeiras 2012. São Paulo.

Fleury, M. T. L.; Fleury, A. C. C. (2004) Alinhando estratégia e competências. RAE, v. 44 , n. 1, p. $44-57$.

Fleury, M. T. L.; Fleury, A. C. C. (2003). Estratégias competitivas e competências essenciais: perspectivas para a internacionalização da indústria no Brasil. Revista Gestão \& Produção, v. 10, n. 2, p. 129-144.

Jappur, R. F.; Campos, L. M. De S.; Hoffmann, V. E.; Selig, P. M. (2008). A Visão de Especialistas Sobre a Sustentabilidade Produtiva. Revista Produção On Line, v. VIII, n. III, p. 24.

Lima, M. C. (2008). Monografia. A engenharia da produção acadêmica. 2nd ed. São Paulo: Saraiva.

Manoel, J.; Carneiro, T.; Ferreira, J. (1997). Porter Revisitado: Análise Crítica da Tipologia Estratégica do Mestre. RAC, v. 1, n. 3, p. 7-30.

Mills, J.; Platts, K.; Bourne, M.; Richards, H. (2002). Strategy and performance: Competing through competences. Cambridge: University Press.

Porter, M. E. (1980). Competitive Strategy : techniques for analysing industries and competitors. New York: Free Press. 
Porter, M. E. (1996) O que é estratégia ? Harvard Business Review, v. 6, p. 1-25.

Prahalad, C. K.; Hamel, G. (1990) The core competence of the corporation. Harvard Business Review1, v. 68, n. 3, p. 79-91.

Richardson, R. J. (1999) Pesquisa Social. 3rd ed. São Paulo: Atlas, 1999.

Sampieri, R. H.; Collado, C. F.; Lúcio, P. B. (2006). Metodologia de Pesquisa. 3rd ed. São Paulo: Ed. McGraw Hill Book Company.

Sharkie, R. (2003) Knowledge creation and its place in the development of sustainable competitive advantage. Journal of Knowledge Management, v. 7, n. 1, p. 20-31, 2003. Harvard Business School Press. Disponível em: <http://search.ebscohost. com/login.aspx?direct=true\&db=bth\&AN=4014267\&site=ehost-live\&scope $=$ site $>$. Acesso em: 9/6/2013.

Simone, L.; Quelhas, O. L. G. (2006). Sustentabilidade empresarial e o impacto no custo de capital próprio das empresas de capital aberto. Revista Gestão \& Produção, v. 13, n. 3, p. 385-395. 